on the part of his friends and himself could have induced him to write this letter, from which I take the following extracts:

. . " The middle classes are suffering frightfully in the present depreciation of money. Our salaries (which are for the present being paid) seem high according to the figures, but they are insufficient for the purchase of even the ordinary necessities of life. We may, for instance, possibly once a week have a bit of meat, but for the rest of the time we have to rejoice if we can get enough bad bread and vegetables to appease hunger. Sugar is enormously dear and never to be had in sufficient quantities. Clothing we can not buy, for a single simple suit would cost more than a month's salary. It is the same with underclothes and shoes. What our present conditions will lead to in the near future it is impossible to conceive."

..." You can imagine it is in the highest degree painful for me to write you such a letter, and only real suffering would justify it."

. . " While we are suffering in Austria from actual need of food, packages of food sent by individuals in America rarely reach their destination. Money is practically of no value, for there is little food to be purchased with it."

Professor - whose name I withhold, writes that the American Relief Administration (whose office in this country is at $\mathbf{1 1 5}$ Broadway, New York), has established an American food warehouse in Vienna, from which food is distributed that has been shipped from this country.

JAS. Lewis Howe

WASHINGTON AND LEE UNIVERSITY, LEXINGTON, VIRGINIA

\section{JOURNALS FOR PRAGUE}

To the Editor of Solence: Dr. M. Kojima, surgeon-commander, Japanese Navy, has but now arrived from Tchecho-Slovak where he visited Professor A. Biedl. The latter has sent through him a message to American scientists asking if they can arrange to have sent to him the various scientific publications and periodicals, since he is unable to purchase the same on account of the rate of exchange, lack of funds, and general disturbed conditions in Tchecho-Slovak. It seems to me that the least we can do is to arrange through our editing boards some procedure by which Dr. Biedl may receive current numbers of our scientific periodicals. I would appreciate greatly your giving this communication publicity in "Science." Dr. Biedl's address is Das Institute fur Experimentelle Pathologie, Prag, Tchecho-Slovak.

Frederick S. Hammett

\section{NOTES ON METEOROLOGY}

THE SUPPOSED RECURRENT IRREGULARITIES IN THE ANNUAL MARCH OF TEMPERATURE

"The belief that periods of unseasonable heat and cold tend to recur at or about the same time from year to year has prevailed over a great part of the world for many centuries and has been the subject of extensive scientific investigation." This is the opening sentence in an extensive, scholarly discussion of the "Literature concerning supposed recurrent irregularities in the annual March of temperature," by C. Fitzhugh Talman, librarian of the Weather Bureau. ${ }^{6}$

Most of the literature deals with a cold period in May.

Over a considerable part of continental Europe it has been popularly believed since the Middle Ages that destructive frosts were likely to occur at a certain period in the month of May, and with the elaboration of the ecclestiastical calendar these frosits became definitely associated with the days dedicated to Saints Miamertus, Pancras and Servatius (May 11, 12, 13), or, in south-central Europe, Saints Pancras, Servatius and Boniface (May 12, 13, 14), hence known as the "ice saints." ... With the construction of synoptic weather charts, the barometric conditions that accompany depressions of temperature gradually became apparent. ... [This cold period] was found to occur when, owing to the rapid warming of the land regions as compared with the ocean, a center of low barometric pressure develops over southeastern Europe while high pressure prevails over the ocean

6 Monthly Weather Review, August, 1919, Vol. 47, pp. 555-565. 